\begin{tabular}{|c|c|}
\hline & $\begin{array}{l}\text { International Journal of Trend in Scientific } \\
\text { Research and Development (IJTSRD) }\end{array}$ \\
\hline 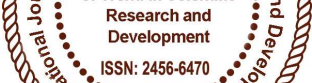 & International Open Access Journal \\
\hline 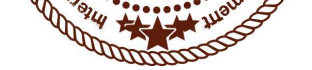 & ISSN No: 2456 - 6470 | www.ijtsrd.com | Volume - 2 | Issue - 2 \\
\hline
\end{tabular}

\title{
A study of correlation between conceptual understanding and achievement in Biology subject of standard $10^{\text {th }}$
}

\author{
Nilesha Sisodiya \\ PGT Biology \\ Podar International School \\ Ahmedabad, Gujarat, India
}

\section{ABSTRACT}

Biology is an important subject at higher secondary level for those students who want to make their career in medical or any related field. An attempt has been made to determine correlation between conceptual understanding and achievement in biology subject in students of standard $10^{\text {th }}$. This will help the students to choose their stream for future study properly and will even help the teachers to guide their students accordingly. A sample of 80 students studying in standard $10^{\text {th }}$ were chosen for this study. After statistical treatment, it revealed that there is high correlation between conceptual understanding and achievement in biology in students of standard $10^{\text {th }}$. However minute differences were found in some cases.

Keywords: Biology, Concepts, Conceptual understanding, Standardized test, Correlation

\section{INTRODUCTION}

Biology is all about studying life and living organisms. We are living organisms and we eat living organisms, so you could probably guess that it has something to tell us about what's going on all around and inside us.

The study of biology owes great significance in human life, because man for its day-to-day requirement is dependent on plants and animals either directly or indirectly.
Why Biology is important to study for high school?

It helps us to get better understanding about the world in its natural processes.

It is study of how lives evolves survives and changes it gives knowledge about the interaction of cell with organs and organisms, environment and ecosystem.

It teaches how various organs and organ system works on human body and how everything is connected in our body

It is an important subject for medical point of view which identifies diseases and its cure knowledge of Biology helps making a better environment to live in

The vast study of Biology has contributed improvement in agriculture.

Often students find Biology as boring subject however it is scoring subject if you adopt the systematic learning approach. The student who aim to make career in life sciences and medicine then they should seriously think about studying the subject right from high school grade.

Instruction of Biology starts at primary level when the young children begin to understand the properties of living being and Diversity. Biology constitute a significant component of science curriculum and is 
studied by all the students till the middle school. At the secondary school (9th and 10th standard) Biology become an important subject. The process of selection starts at Higher Secondary Level (11th and 12th standard) with a largely Irreversible selection of future choices. Student who desire to prepare for career in medicine practice usually select Biology as one of their subject at Higher Secondary Level.

In today's world each student who has opt for Biology wants to be a doctor or build up their career very fast and to earn more. For this they have to appear for entrance exams. Parents of students also want this but before taking any particular decision, they do not think about student's capability or abilities. So in the craze with bright future with this subject after 10 th they are taking science stream for further education. But in general it is not always true that the student who has got good result in 10th will get success in higher standards and the result will be as per their dreams.

To be successful in life, good marks is not the only criteria but in Gujarat we have this type of system in which good marks is the only criteria to get admission in any branch of science stream. It is easy to get good marks but it does not reflect students understanding and mainly the conceptual understanding. Conceptual understanding is required because nowadays the student have to face the entrance exam. So here I have tried to find whether there is any correlation between conceptual understanding and the marks of Biology in 10th standard.

According to Piaget, without conceptual understanding any type of mental activity cannot be done by students. Biology is a subject which is fully filled with concepts and before giving answers of any question of Biology, students should possess appropriate mental ability. In such a context it is imperative that the concept of Biology should be very much clear and well understood by the student of this generation.

Being a biology teacher of std 10 researcher found that students were not interested in studying biology subject. Their scores were very low and they were not ready to take part in discussion.

The researcher diagnosed that their concepts are not clear in biology. So the researcher changed the way of teaching and switched to ICT (i.e use of PPT and Videos ) to teach each concept.

Researcher searched for all the concepts and taught those concepts with the help of PPTs and videos. Researcher observed the change in students behavior, attitude and liking towards biology. They started liking the subject and even their scores in achievement in biology increased with increase in understanding. The researcher found the correlation between scores of conceptual understanding test and scores of achievement in Biology subject.

\section{Statement of the problem}

As to find out the correlation of conceptual understanding and marks obtained in biology investigator has selected the following problem for her research work.

"A study of correlation between conceptual understanding and achievement in Biology subject of standard $10^{\text {th }}$."

\section{Importance of the study}

As the study is related to biology the subject itself is an important one. Apart from this the present study is also related to biological concepts, the study implies a great impact in the education field.

This test useful to find if there is any correlation between conceptual understandings in biology of student with the marks achieved in biology by the student. As mentioned earlier always students select the stream for further education according to their result, but result is memory based and there would not be real biological conceptual understanding. So it can be used to guide the students about their future selection of stream. It will help them to find if they have the scientific aptitude for future selection. This will even help the teacher to find that the marks and conceptual understanding of the students are related or not and can instruct or guide accordingly.

After completion of the study researcher found the correlation in conceptual understanding and achievement in biology, separately for boys and Girls.

\section{Objectives of the study}


For any specific study there is a precise motive or objective. No goal is achieved without any specific objective. There is no meaning of research without any precise objective. An objective of a research direct and organizes the path of research objectives gives a specific direction to research. It helps in pinpointing our problems and show a clear path of procedure. As in this study correlation is to be found between conceptual understanding and achievement in Biology subject of standard 10th following objectives are listed for the study.

To find correlation between scores of conceptual understanding and scores of achievement in Biology subject in students of standard $10^{\text {th }}$

$>$ To find correlation between scores of conceptual understanding and scores of achievement in Biology subject in boys of standard $10^{\text {th }}$

$>$ To find correlation between scores of conceptual understanding and scores of achievement in Biology subject in girls of standard $10^{\text {th }}$

\section{Hypothesis}

Hypothesis is a step towards the solution of the problem. Hypothesis help the researcher to get rid of unnecessary information and literature. Hypothesis help in finding solution and also guides in the research which is necessary for the researcher. Hypothesis statement that can be tested statistically. Hypothesis usually makes predictions about future events existing difference among group of existing relationship among variables.

"In order to focus our information gathering we try to identify possible solutions or explanation to our problem and then gather the information needed to see if a given explanation is correct. These educated guesses about possible differences, relationship or causes are called hypothesis. Hypothesis reflect the research workers guess as to the problem outcome of the experience." 1

Following are the hypothesis listed for this study in contacts to above-mentioned objectives

Hypothesis 1 - There is no significant correlation in conceptual understanding of biology and achievement in Biology subject in std $10^{\text {th }}$ students
Hypothesis 2 - There is no significant correlation in conceptual understanding of biology and achievement in Biology subject in std $10^{\text {th }}$ boys.

Hypothesis 3- There is no significant correlation in conceptual understanding of biology and achievement in Biology subject in std $10^{\text {th }}$ girls

\section{Definition of keywords}

1. Biology

"The word Biology is derived from Greek word Bios means life and logos meaning study is defined as signs of life and living organism".2

\section{Concepts}

"Concepts are mental categories used to group objects, events, information, etc. It is the way people see and understand something the name used for concept is a term".3

"A concept is an idea generalized from particular and relevant experiences and is called the product of science." 4

\section{Conceptual understanding}

"Conceptual understanding means to understand the concept properly. It is knowing more than isolated facts and methods. The successful students understand ideas and has ability to transfer their knowledge into new situation and apply it into new context." ${ }_{5}$

"Conceptual understanding means that the student understand which ideas are the key and that they grasp the heuristic value of them strategically to solve problems specially non routine problems and avoid common miss understanding as well as in flexible knowledge and skills." 6

\section{Standardized test}

"A test for which content has been selected and checked empirically for which norms have been established, for which uniform method of Administration and scoring have been developed which may be scored with a relatively high degree of objectivity."7

\section{Correlation}

"Correlation is a statistical technique that can show whether and how strongly pairs of variables are related." 8 
Correlation is a bivariate analysis that measures the strength of association between two variables and the direction of the relationship. In terms of the strength of relationship, the value of the correlation coefficient varies between +1 and -1 . A value of \pm 1 indicates a perfect degree of association between the two variables. As the correlation coefficient value goes towards 0 , the relationship between the two variables will be weaker. The direction of the relationship is indicated by the sign of the coefficient; $a+$ sign indicates a positive relationship and $\mathrm{a}-$ sign indicates a negative relationship.9

\section{Variables}

As this is a test to find correlation there are no dependent and independent variables.

Here we will try to find the correlation of marks obtained in conceptual understating test and achievement in biology in $10^{\text {th }}$. And correlation among marks obtained in conceptual understating test and achievement in biology in boys and girls. So the variables are scores of conceptual understanding and scores of achievement in biology.

\section{Population and sample}

From the statement it is clear that student of 10th standard become the population of the study.

Sample selection

As researcher work with Podar International school, and want to take small sample so she has taken 80 students of standard $10^{\text {th }}$ of the same school as the sample of the study. Out of this 80 , no of Boys were 38 and no of girls were 42

\section{Selection of test}

In this researcher had selected scientific concept understanding test which is a standardized test prepared by Dr Vaishalib Sheth,, to find the conceptual understanding in science for class 10 .

This test contains 121 test items divided in 4 units. These test items are objective type questions based on all chapters from science textbook of standard 9. Out of this 121 items the researcher selected 25 items of unit 2 which contain questions based on biology to find conceptual understanding in Biology subject in students of std $10^{\text {th }}$.
For scores of achievement test in biology the researcher had collected the data from the result of science exam in the school and used only the score of biology related questions from it.

\section{Data collection}

The researcher gave the test to selected sample and collected the data from it. The researcher even collected their scores in biology subject in their recent exam.

\section{Analysis of data}

Analysis of the data was done by the Pearson $r$ correlation (Product-moment coefficient of correlation) method.

The Pearson product-moment correlation coefficient (or Pearson correlation coefficient, for short) is a measure of the strength of a linear association between two variables and is denoted by $r$. Basically, a Pearson product-moment correlation attempts to draw a line of best fit through the data of two variables, and the Pearson correlation coefficient, $r$, indicates how far away all these data points are to this line of best fit (i.e., how well the data points fit this new model/line of best fit). 10

This procedure is used because the data is ungrouped, which does not require use of deviations. It deals entirely with original scores. The scores were small in number so this method was used. The following formula is used to calculate the Pearson $r$ correlation

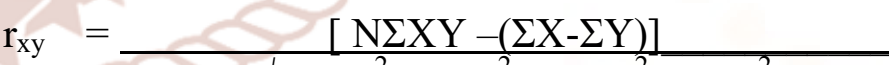 $\sqrt{ }\left[\mathrm{N} \Sigma \mathrm{X}^{2}-\left(\Sigma(\mathrm{X})^{2}\right]\left[\mathrm{N} \Sigma \mathrm{Y}^{2}-\left(\Sigma(\mathrm{Y})^{2}\right]\right.\right.$}

Here $\mathrm{X}$ and $\mathrm{Y}$ are original scores in Variable $\mathrm{X}$ achievement in biology and $\mathrm{Y}$ - is conceptual understanding in biology. Other symbols tell what is done with them.11

1. Researcher found the correlation of scores of achievement in biology and scores of conceptual understanding in biology in students of standard $10^{\text {th }}$.

2. Researcher found the correlation of scores of achievement in biology and scores of conceptual understanding in biology in boys of standard $10^{\text {th }}$. 
3. Researcher found the correlation of scores of achievement in biology and scores of conceptual understanding in biology in girls of standard $10^{\text {th }}$.

4. The researcher found the mean of scores of conceptual understanding test and achievement test and biology.

5. The researcher found the Standard deviation of scores of conceptual understanding test and achievement test and biology.

\section{Findings}

1. Researcher found the correlation of scores of achievement in biology and scores of conceptual understanding in biology in students of standard $10^{\text {th }}$ is 0.84

2. Researcher found the correlation of scores of achievement in biology and scores of conceptual understanding in biology in boys of standard $10^{\text {th }}$ is 0.84

3. Researcher found the correlation of scores of achievement in biology and scores of conceptual understanding in biology in girls of standard $10^{\text {th }}$ is 0.81

4. The mean of conceptual understanding is 16.65 and its standard deviation is 3.30

5. The mean of achievement in biology is 13.45 and standard deviation is 4.16

\section{Interpretation}

Ho1 - There is no significant correlation in conceptual understanding of biology and achievement in Biology subject in std $10^{\text {th }}$ students.

Researcher found the correlation between scores of achievement in biology and scores of conceptual understanding in biology is 0.84 , which shows high correlation between conceptual understanding of biology and achievement in biology.

So Hol is rejected and the researcher decided that there is high correlation between conceptual understanding of biology and achievement in biology subject in std $10^{\text {th }}$ students.

Ho2 - There is no significant correlation in conceptual understanding of biology and achievement in Biology subject in std $10^{\text {th }}$ boys.
Researcher found the correlation between scores of achievement in biology and scores of conceptual understanding in biology in boys of std $10^{\text {th }}$ is 0.84 which shows high correlation between conceptual understanding of biology and achievement in biology.

So Ho2 is rejected and the researcher decided that there is high correlation between conceptual understanding of biology and achievement in biology in std $10^{\text {th }}$ boys.

Ho3- There is no significant correlation in conceptual understanding of biology and achievement in Biology subject in std $10^{\text {th }}$ girls.

Researcher found the correlation between scores of achievement in biology and scores of conceptual understanding in biology in girls of std $10^{\text {th }}$ is 0.81 which shows high correlation between conceptual understanding of biology and achievement in biology.

So Ho3 is rejected and the researcher decided that there is high correlation between conceptual understanding of biology and achievement in biology in $\operatorname{std} 10^{\text {th }}$ girls.

\section{Suggestion}

This correlation can be used to give suggestion to the students for their future stream selection. It can also be used to suggest teachers that the achievement in biology is highly correlated to the conceptual understanding in biology, so they have to give more focus on clearing the concepts of the students rather than scores in exam. As the conceptual understanding and achievement in biology are highly correlated if concepts are clear they will score good in their exams.

\section{Delimitation of the study}

Delimitation are the boundaries which are purposefully put on the study usually to narrow it for research ability.

The study was confined to the following boundaries present study was

$>$ Limited for students studying in standard $10^{\text {th }}$.

$>$ Only student from one school where used for the study 
International Journal of Trend in Scientific Research and Development (IJTSRD) ISSN: 2456-6470

\section{References :}

1) Walter R. Borg \& Gall M.D., (1983) Educational Research-An Introduction (p.87) Newyork: Longmen

2) Mary Bagley, Live Science Contributor (2017, August 9). Livescience[web log bost] Retrieved from https://www.livescience.com/44549-what-isbiology.html

3) http://general-psychology.weebly.com/how-areconcepts-formed.html

4) A.A. Carin,R.B.Sund,(1989)Teaching science through Discovery (p.12) Colombus:Merrill publishing

5) Cathy Fosnot, dreambox learning (2017) [web log bost] Retrieved from

6) https://www.dreambox.com/conceptualunderstanding/
7) Grant Wiggins,(2014,23 April) Conceptual understanding in Mathematics

8) https://grantwiggins.wordpress.com/2014/04/23/c onceptual-understanding-in-mathematics/

9) Jasmin Ahmed,(2011)Teacheing of Biology Sciences (p 267)New Delhi:PHL learning

10) https://www.surveysystem.com/correlation.htm

11) http://www.statisticssolutions.com/correlationpearson-kendall-spearman/

12) https://statistics.laerd.com/statisticalguides/pearson-correlation-coefficient-statisticalguide.php

13) J.P. Guilford, (1956) Fundamental statistics in psychology and education (p.140) Japan:McGrawHill

14) Vaishali Sheth(1998)A comparative study of understanding of scientific concepts of the student of std $10^{\text {th }}$ of English and Gujarati medium schools of Ahmedabad city, M.Ed., Gujarat University-unpublished 